\title{
Temettü Tahmini ve Borsa İstanbul Sanayi Sektörü Üzerine Bir Araştırma
}

\author{
Mustafa Fatih ARSOY, Birol YILDIZ
}

Temettü Tahmini ve Borsa İstanbul Sanayi Sektörü Üze-
rine Bir Araştırma

Özet

Çalışmanın amacı, Borsa İstanbul (BiST)'da işlem gören sanayi işletmelerinin temettü politikasını yönlendiren etkenleri saptamak ve gelecekte yapılacak temettü ödemesini tahmin etmektir. Çalışmada Borsa İstanbul (BiST)'da işlem gören 168 sanayi işletmesinin 2003-2012 yılları arasındaki verileri kullanılarak çoklu doğrusal regresyon analizi yapılmış, temettü politikasını etkileyen önemli değişkenler saptanmış ve temettü ödemesinin tahmininde kullanılabilecek bir model elde edilmiştir. Çalışma sonucunda elde edilen çoklu doğrusal regresyon modelinin değişkenlere ait geçmiş dönem değerlerini kullanarak, cari dönemde nakit ödenen brüt temettü oranını başarıı şekilde tahmin ettiği görülmüştür. Oluşturulan bu model, Lintner modeli, sinyalizasyon, serbest nakit akışı ve yaşam döngüsü olarak bilinen temettü politikası teorilerini destekleyen sonuçlar ortaya koymuştur.

Anahtar Kelimeler: Temettü Politikası, Borsa İstanbul, Temettü Ödemesi, Nakit Temettü Ödeme Oranı
Predicting Corporates' Dividends and an Empirical Study on Borsa Istanbul Industry Sector

\section{Abstract}

The aim of this study is to determine the factors which have an impact on firms' dividend policies and develop a model to predict the dividend payments of industrial firms which are quoted on Borsa Istanbul (BIST). To reach this aim, a multiple linear regression (MLR) analysis was carried out on data collected between 2003 and 2012 from a sample of 168 publicly traded industrial firms on BIST. Important variables affecting the dividend policy was determined and a model that can be used to estimate the dividend payment was composed. As a result it is seen that, by using the past values of variables, the model can predict the gross cash dividend rate paid in the current period, successfully. The revealed results of this model supports existing dividend policy theories like Lintner's model, signaling, free cash flows and life cycle theories.

Key Words: Dividend Policy, Borsa Istanbul, Dividend Payout, Cash Dividend Payout Ratio

\section{Giriş}

İşletmelerin uzun vadede izleyecekleri temettü dağıtım oranını belirlemek, bu oranı işletmenin piyasa değerini en yüksek düzeye çıkaracak biçimde oluşturmak, elde edilen kârın hissedarlara dağıtılması veya yatııımlar için işletmede alıkonulması kararlarını vermek, temettü dağıtım politikasının özünü meydana getirmektedir. Yatıımcılar işletmelerin raporladığı finansal verileri güvenilir bulmadıkları için, işletmelerin gelecek performansını değerlendirmede dağıtılan temettüleri temel alan bir yaklaşımı tercih etmektedirler. Bu bağlamda düzenli temettü dağıtan bir işletmeyi, düzensiz temettü dağıtan işletmelere göre daha risksiz ve güvenilir bulan yatıımcılar, temettü dağıtımı istikrarlı olan işletmeleri daha değerli buldukları için, bu işletmelerin hisse değeri diğerlerine göre daha yüksek olabilmektedir.

\footnotetext{
* Mustafa Fatih ARSOY, Dr., Kara Harp Okulu, İşletme Bölümü, mfarsoy@kho.edu.tr; Birol YILDIZ, Doç.Dr., Eskişehir Osmangazi Üniversitesi, İşletme Bölümü, byildiz@ogu.edu.tr
} 
Belirtilen teorik gerekçeler dışında, diğer gelişen ülkelerden daha yüksek enflasyonist baskı altında olan ve yüksek kırılganlığa sahip Türkiye gibi gelişmekte olan sermaye piyasalarında, riskten kaçınan yatırımcılar temettüleri işletmelerin geleceğine ilişkin mesaj veren en önemli faktörlerden biri olarak algılamakta ve hisse senetleri piyasasında yatırım kararlarını buna göre vermektedirler. Dolayısıyla Türkiye'de halka açık işletmeler tarafından yüksek oranda ve sürekli dağıtılan temettüler, kurumsal ve bireysel yatırımcılar açısından daha fazla önem kazanmaktadır.

Yukarıdaki bilgileri çıkış noktası alan bu çalışmada, Türkiye'de halka açık sanayi işletmelerinde nakit temettü ödemelerini hangi etkenlerin yönlendirdiğini belirlemek, varlığı bilinen temettü politikası teorilerinin geçerliliğini araştırmak ve yatırımcılara hisse senedi yatııımlarında yararlanabilecekleri nakit temettü ödeme oranını açıklayabilen bir model geliştirmek amaçlanmıştır.

Çalışmanın amacını gerçekleştirmek için, hisse senetleri Borsa İstanbul'da işlem gören sanayi sektöründeki işletmelerin verileri kullanılmıştır. Öncelikle literatürdeki araştırmalardan yararlanarak temettü ödemesi ile anlamlı ilişkisi olduğu tespit edilen değişkenlerin geniş bir listesi oluşturulmuştur. Literatüre konu olan değişkenlerin hemen tümü bu listede yer bulmuştur. Ardından cari dönemde ( $t$ ) nakit ödenecek brüt temettü oranı bu değişkenlere ait bir önceki dönem ( $t-1)$ verileri kullanılarak, farklı çoklu doğrusal regresyon (ÇDR) modelleri ile tahmin edilmeye çalışılmıştır. Son olarak modellerin ortalama mutlak hata yüzdesi (OMHY) değerleri karşılaştırılarak, ödenecek brüt temettü oranını en iyi tahmin eden model belirlenmiştir.

Çalışmanın ikinci bölümünde literatürde yer alan temel temettü politikası teorileri ve temettü dağııımını yönlendiren etkenlere yönelik yapılmış amprik çalışmalar özetlenmiştir. Uygulamada kullanılan veri üçüncü bölümde açıklanmıştır. Araştırmanın kapsamı ve yöntemi dördüncü, analizler sonucu elde edilen bulgular ise beşinci bölümde yer almaktadır. Altıncı bölümde ulaşılan sonuçlar ortaya konulmuştur.

\section{Literatür Taraması}

\subsection{Temettü Politikası Teorileri}

Finans literatüründe işletmelerin uyguladığı temettü politikasının yatırımcılar ve dolayısıyla hisse senetleri üzerinde olumlu veya olumsuz bir etkisi olduğunu savunan birçok teori ileri sürülmüştür.

Yüksek miktarda temettü dağıtımının sermaye maliyetini azaltarak işletme değerini artırdığını ileri süren eldeki kuş teorisine (Gordon ve Shapiro, 1956) göre, temettüler hisse senedi fiyatları üzerinde dağıtılmamış kârlardan daha büyük bir etkiye sahip olduğundan, hissedarlar yüksek temettü politikasını tercih edeceklerdir. Gordon (1962), Walter (1963) ve Diamond (1967) çalışmalarında bu teoriyi destekleyen bulgular elde etmişlerdir.

Düşük temettü dağııım oranlarının sermaye maliyetini azalttığını ve hisse senedi fiyatını yükselttiğini savunan vergi etkisi teorisine (Brennan, 1970, Litzenberger ve Ramaswamy, 1979) göre, birçok 
ülkede sermaye kazançlarının tabi olduğu vergilere kıyasla, temettülere daha yüksek vergi uygulanmaktadır. Bu yüzden yüksek vergi dilimindeki yatırımcı, daha yüksek temettü getirili hisse senetlerini elde tutmak için, vergi öncesi riski düzeltilmiş daha yüksek getirilere ihtiyaç duymaktadır; temettü gelirleri vergiden muaf tutulan kurumsal yatırımcı da yüksek temettü getirisi sağlayan işletmelere yönelmektedir. Bir başka deyişle, yatırımcılar kendi vergi koşullarına en uygun temettü politikasına sahip işletmelere yönelmektedirler. Poterba ve Summers (1984), Allen vd.(2000), Seida (2001), Baker vd. (2002), Renneboog ve Trajonowski (2010), Gill vd. (2010) ve Jeong (2013), çalışmalarında verginin temettü kararları üzerinde önemli bir etkiye sahip olduğunu tespit etmişlerdir.

İşlem maliyetleri teorisine (Pettit, 1977) göre tüketim ihtiyaçları için temettü gelirine güvenenen emekliler ve maaş ile geçinen küçük yatırımcılar, hisse senetlerini satmaya yönelik işlem maliyetleri yüksek olabileceğinden, yüksek ve istikrarlı temettü dağıtan hisse senetlerini daha cazip bulmaktadırlar. İşlem maliyetleri açısından temettü tercihi, demografik özelliklere bağlı olarak da farklılık gösterebilmektedir. Genellikle yaşı, gelir düzeyi düşük ve üniversite eğitimi almamış yatıımcılar, işlem maliyetlerinden kaçınmak için yüksek temettü talep ederken, genç, yüksek gelire sahip ve üniversite eğitimi almış yatırımcılar da ise bir güdüye bağlı olmadan yüksek temettü getirisi talep edilmektedir. Diğer taraftan likidite ihtiyaçlarını karşılamak için hisse senedi portföylerine bağlı kalmayan zengin yatıımcılar, temettülerin tekrar yatııma yönlendirmeye ilişkin işlem maliyetlerinden sakınmak amacıyla, düşük temettü dağıtımını tercih etmektedirler. Michael (1979), Fazzari vd. (1988), Bishop vd. (2000), Dong vd. (2005)'un bulguları işlem maliyetleri teorisini desteklemektedir.

Temettü beyanlarının ve değişikliklerinin değerli bilgi taşıdığını ileri süren sinyalizasyon teorisine (Pettit, 1972, Laub, 1976 ve Bhattacharya, 1979) göre yatırımcılar, hem temettülerin istikrarı, hem de temettü değişiklikleri açısından, temettü beyanlarından gelen sinyal aracılığıyla işletmelerin gelecek kârları hakkında bilgi çıkarımında bulunabilmektedirler. İşletmeler temettü politikasını gelecek görünümleri hakkında piyasaya bilgi iletmek için kullanmakta ve dolayısıyla sinyalizasyon teorisi işletmelerin temettü politikalarının ve değerlerinin belirlenmesinde önemli bir rol oynayabilmektedir. Woolridge (1983), John ve Williams (1985), Aivazan vd. (2003), Dong vd. (2005) ve Jeong (2008) çaIışmalarında bilgi asimetrisi ve sinyalizasyon teorisi ile uyumlu bulgular elde etmişlerdir.

Temsil maliyetleri teorisine (Rozeff, 1982, Easterbrook, 1984 ve Jensen, 1986) göre hissedarların yöneticilerin davranışını gözetlemeye yönelik katlandıkları temsil maliyetleri, aslında işletme yöneticileri ile hissedarlar arasındaki potansiyel menfaat çatışmasından kaynaklanan maliyetlerdir. Temettü dağıımı, yöneticilerin kontrolü altındaki isteğe bağlı fonları azaltmak suretiyle yöneticiler ile hissedarlar arasındaki temsil problemlerini yatıştırmakta ve çıkarları aynı seviyeye getirmektedir. Dolayısıyla daha fazla temettü dağıtılması, yöneticiler ve hissedarlar arasındaki temsil maliyetlerini azaltacaktır. Jensen vd. (1992), Holder vd. (1998), La Porta vd. (2000), Denis ve Osobov (2008), Brockman ve Unlu (2009), Al-Kuwari (2009), Ma (2012) ve Abuhommous (2013) çalışmalarında temsil maliyetleri teorisini destekleyen bulgulara ulaşmışlardır.

Temettü politikası ile yatırım politikasının ilişkili olduğunu savunan serbest nakit akışı teorisi (Jensen, 1986) ise dağıtılan temettü miktarındaki artışın artık-fazla yatırım problemini azaltacağını ve 
Mustafa Fatih ARSOY | Birol YILDIZ

diğer koşullar aynı iken, işletmenin piyasa değerini olumlu etkileyeceğini ileri sürmektedir. Lang ve Litzenberger (1989), Holder vd. (1998), Benito ve Young (2003), DeAngelo ve DeAngelo (2006), Denis ve Osobov (2008), Parua ve Gupta (2009), Issa (2012), Ma (2012) ve Abdoua vd. (2012) araştırmalarında serbest nakit akışlarının işletmelerin temettü politikasını belirleyen etkenlerden biri olduğunu tespit etmişlerdir.

Fama ve French (2001)'in araştırması ile literatüre giren yaşam döngüsü teorisine göre, işletmenin yaşam döngüsünün içinde bulunduğu aşama, temettü dağıtım kabiliyetinin iyi bir göstergesi olmaktadır. Teori göreli yüksek kârlılık ve düşük büyüme oranlarına sahip, olgunluk evresindeki, büyük ve istikrarlı işletmelerin çok fazla nakit üretmesine ragmen, fazla kârlı yatırım fırsatı bulamaması nedeniyle daha çok temettü dağıttığını, bununla birlikte hayatlarının erken dönemlerinde, düşük karı olan, birçok yatırım fırsatına sahip küçük ölçekli işletmelerin ise daha düşük miktarda temettü dağıttığını ileri sürmektedir. Grullon vd. (2002), DeAngelo vd. (2006), Denis ve Osobov (2008), Brockman ve Unlu (2009), Coulton ve Ruddock (2011), Ma (2012), Banyi ve Kahle (2013), Çelik (2013) ve Abuhommous (2013) çalışmalarında yaşam döngüsü teorisini destekleyen bulgular tespit etmişlerdir.

İşletmelerin temettü davranışını davranışsal perspektiften açıklayan aktarma teorisi (Baker ve Wurgler, 2004a ve 2004b) ise işletmelerin temettü dağıtma olasılığının, yatıımcıların temettü dağıtan ya da dağıtmayan işletmeleri tercih etmelerine bağlı olduğunu varsaymaktadır. Buna göre yöneticiler, temettü dağıtan hisse senetlerine yatırımcılar prim verdiği zaman temettü dağıtmak suretiyle veya yatırımcıların temettü dağıtmayan hisse senetlerini tercih etmeleri durumunda temettü dağıtmamak suretiyle, yatırımcıların temettü talebine karşılık vermektedirler (Li ve Lie, 2006). Ancak Kuo vd. (2013) temettü politikasını belirlemede aktarma motivasyonun sadece geleneksel hukuk sistemi geçerli olan ülkelerdeki işletmelerde devam ettiğini tespit etmişlerdir.

\subsection{Temettü Politikasını Etkileyen Etkenlere Yönelik Araştırmalar}

Temettü politikalarının geçerliliğini ve işletmelerin temettü dağıtım kararlarını yönlendiren etkenleri farklı dönemlerde ve farklı özelliklere sahip piyasalarda istatistiksel ve ekonometrik yöntemler ile sorgulayan birçok amprik çalışma yapılmıştır.

Literatürde temettü politikası konusunda önemli bir dönüm noktası teşkil eden ilk amprik çalışmada Lintner (1956), işletmelerin uzun vadeli hedef temettü dağıtım oranlarına sahip olduğunu, istikrarlı kazanca sahip olgun işletmelerin genellikle karlarının yüksek bir oranını dağıttığını, ancak büyüyen işletmelerin düşük ödeme yaptığını saptamışlardır. Ayrıca yöneticilerin mutlak temettü dağıtım düzeyinden ziyade, temettü değişiklikliklerine odaklandığını, temettü değişikliklerinin uzun vadeli kanıtlanabilir kârlardaki değişimleri takip ettiğini, yöneticilerin temettü miktarını azaltmaya çaısştığını tespit etmiştir. Dağıtılan temettünün bir kısmının işletmenin cari kârına, bir kısmının ise önceki yıl dağıtılan temettüye bağımlı olduğunu gösteren Lintner'in modeli, işletmelerin uzun vadeli hedef temettü dağıtım oranlarına sahip olduğu varsayımına dayanmıştır. Lintner'in temettü düzeltme bulgusu, daha sonra yapılan birçok çalışma ile teyid edilmiştir. Bu çalışmalardan bazıları Fama 
ve Babiak (1968), Laub (1976), Farrelly vd. (1986), Brav vd. (2005) ve Leary ve Michaely (2011) şeklinde sıralanabilir.

Temettü dağıtımının asıl belirleyicisinin işletmelerin kâr düzeyi olduğunu kanıtlayan çok fazla sayıda amprik çalışma bulunmaktadır. Bu kapsamda Lintner (1956), Adaoğlu (2000), Benito ve Young (2003) ve Baker ve Smith (2006) cari kâr, Farrelly vd. (1986) gelecekte beklenen kâr düzeyi, Fama ve French (2001), Aivazan vd. (2003), DeAngelo vd. (2004), Mitton (2004), Kania ve Bacon (2005), Renneboog ve Trojanowski (2005), Von Eije ve Megginson (2006), Li ve Lie (2006), Denis ve Osobov (2008), Kim ve Gu (2009), Al-Kuwari (2009), Gill vd. (2010), Renneboog ve Trajonowski (2010), Coulton ve Ruddock (2011), Fatemi ve Bildik (2012), Ma (2012), Çelik (2013) ve Abuhommous (2013) kârlılık, Pruitt ve Gitman (1991) cari ve geçmiş yıllara ait kârlar ile kardaki büyüme, Goergen vd. (2005), Parua ve Gupta (2009) geçmiş dönem, cari ve gelecekte beklenen kâr düzeyi, Issa (2012) aktif kârlıı̆̆ı, özsermaye kârlıığı ve hisse başına kâr, Salehi vd. (2012) faaliyet kârı, vergi sonrası kâr, özsermaye kârılı̆̆ı ve satışların kârııığı etkenleri ile işletmelerin temettü dağıtım kararı arasında anlamlı ilişki olduğunu gösteren bulgular elde etmişlerdir.

Varlıklarda, satışlarda veya yatııımlarda yaşanan büyüme dolayısıyla işletmelerin finansman hiyerarşisine uygun davranmasının, temettü dağıtım kararını etkilediğini gösteren bir çok araştırma yapılmıştır. Bunlar Lintner (1956), LaPorta vd. (2000), Mitton (2004), Kania ve Bacon (2005) ve Jeong (2013) büyüme, Rozeff (1982) yatırım politikası, Gill vd. (2010) satışların büyümesi, Benito ve Young (2003), Renneboog ve Trojanowski (2005), Von Eije ve Megginson (2006), Denis ve Osobov (2008), Kim ve Gu (2009), Huang vd. (2010), Coulton ve Ruddock (2011) ve Fatemi ve Bildik (2012) yatırım (büyüme) fırsatları, Aivazan vd. (2003) ve Ma (2012) varlıkların büyüme oranı ve piyasa değeri defter değeri oranı, Li ve Lie (2006), Issa (2012), Abdoua vd. (2012) ve Abuhommous (2013) piyasa değeri defter değeri oranı, Jeong (2008) ise büyüme fırsatları ve satışlardaki büyüme etkenlerinin temettü politikası üzerinde anlamlı etkileri olduğunu tespit etmişlerdir.

Literatürde istikrarın, temettü politikasının temel bileşenlerinden biri olduğunu kanıtlayan birçok araştırma olduğu da görülmektedir. Lintner (1956), Pruitt ve Gitman (1991), Baker ve Smith (2006), Kim ve Gu (2009) ve Abuhommous (2013) kâr istikrarının, Parua ve Gupta (2009) ise temettü istikrarını sürdürme isteğinin, temettü kararını belirleyen temel etkenlerden biri olduğu bulgusuna ulaşmışlardır.

Yapılan çalışmaların birçoğunda işletme büyüklüğünün diğer bir ifadeyle ölçeğinin temettü kararını belirleyen kilit etkenlerden biri olduğu anlaşılmaktadır. Bu çalışmalara Aivazan vd. (2003), Mitton (2004), Renneboog ve Trojanowski (2005), Von Eije ve Megginson (2006), Li ve Lie (2006), Denis ve Osobov (2008), Al-Kuwari (2009), Kim ve Gu (2009), Huang vd. (2010), Coulton ve Ruddock (2011), Fatemi ve Bildik (2012), Salehi vd. (2012), Ma (2012), Issa (2012) ve Jeong (2013) örnek verilebilir.

Riskin temettü dağııımını anlamlı şekilde etkilediği de bir çok amprik çalışmada teyid edilmektedir. Bu konuda Rozeff (1982), Kania ve Bacon (2005), Von Eije ve Megginson (2008), Issa (2012), Abdoua vd. (2012), Kuo vd. (2013) ve Jeong (2013) işletme riski (beta katsayısı), Ma (2012) ise risk 
Mustafa Fatih ARSOY | Birol YILDIZ

sermayesi desteği etkenlerinin temettü politikası üzerinde anlamlı etkileri olduğunu tespit etmişlerdir.

Literatürde işletmelerin likidite yapısının temettü dağıtma kararını belirleyen etkenlerden biri olduğu görülmektedir. Kania ve Bacon (2005) nakit bulundurma derecesi, Kim ve Gu (2009), Kuo vd. (2013) likidite durumu, Li ve Lie (2006) ve Çelik (2013) nakit oranı, Salehi vd. (2012) ise asit-test oranı ile temettü dağıtma kararı arasında anlamlı ilişki olduğunu gözlemişlerdir.

Crutchley ve Hansen (1989), Aivazan vd. (2003), Renneboog ve Trojanowski (2005), Li ve Lie (2006), Kim ve Gu (2009), Al-Kuwari (2009), Gill vd. (2010) ve Ma (2012) çalışmalarında işletmelerin kaldıraç oranı ile temettü dağıtma kararı arasında anlamlı bir ilişki olduğu bulgusuna ulaşmışlardır.

İşletmelerin mülkiyet yapısı da literatürde sıkça incelenen temettü politikası bileşenlerinden biridir. Yapılan amprik çalışmalarda Rozeff (1982) içeridekilerin mülkiyet düzeyi ve hissedar sayısının, Bancel vd. (2005) mülkiyet yapısının, Khan (2006) mülkiyet yoğunluğunun, Ma (2012) kurumsal mülkiyetin, Ferris vd. (2009) azınlık hissedar durumunun, Al-Kuwari (2009) kamu mülkiyetinin, Jeong (2013) büyük ortak mülkiyetinin, Abuhommous (2013) ise temettü dağıtımını engelleyen hissedar mülkiyetinin, temettü politikası üzerinde anlamlı etkisi olduğunu tespit etmişlerdir.

Geçmiş dönemlerde dağıtılan temettülerin işletmelerin temettü dağıtma kararını belirleyen en önemli etkenlerden biri olduğu yapılan araştırmalardan anlaşılmaktadır. Lintner (1956) önceki yıl dağıtılan temettüleri, Farrelly vd. (1986) ve Baker ve Smith (2006) geçmiş dönemdeki temettü yapısının, Li ve Lie (2006) geçmiş dönem temettü getirisinin, Parua ve Gupta (2009) ise son üç yılda ödenen ortalama temettü miktarının, cari yılda dağıtılacak temettüleri belirleyen en önemli etkenlerden biri olduğunu gözlemişlerdir.

Lintner (1956) işletmenin içinde bulunduğu gelişme aşamasının, DeAngelo vd. (2004) ise işletme yaşının, temettü kararında kilit belirleyici etken olduğunu tespit etmişlerdir.

Temettü politikalarının sektörlere göre farklılaştığını ileri süren Michael (1979)'ın bulguları, Gill vd. (2010), Fatemi ve Bildik (2012) ve Issa (2012)'nın çalışma bulguları ile desteklenmektedir.

Michael (1979) ve Ang vd. (1991) çalışmalarında temettü politikalarının yatıımcıların tercihlerinden bağımsız olamayacağını ifade etmişlerdir.

Aivazan vd. (2003), Bancel vd. (2005), Ferris vd. (2009) ve Jeong (2013) ülkelerin yasal ve kurumsal yapısının, temettü davranışı üzerinde anlamlı etkisi olduğunu gösteren bulgular elde etmişlerdir.

Ma (2012) araştırma ve geliştirme harcamaları ile teknoloji yoğunluğunun bir işletmenin temettü dağıtma eğilimi üzerinde negatif bir etkiye sahip olduğunu tespit etmiştir.

Jeong (2013) ise, faiz oranlarının da temettü düzeltme derecesi ile anlamlı pozitif ilişki içinde bulunduğu sonucuna ulaşmıştır. 


\section{Veri}

Bu araştırmanın çalışma evrenini, hisse senetleri BiST'de işlem gören ve temettü dağıtan işletmeler oluşturmaktadır. Ancak mali kuruluşlar, ticaret ve hizmet işletmeleri farklı özellikler taşıdığı için bu veri kümesinden çıkarılmıştır. Geriye temettü dağıımının yaygın olduğu BisT sanayi sektöründeki işletmelerden oluşan veri seti örneklem olarak kullanılmıştır. Türkiye Ekonomisi'nde 1990'lı yıllardaki krizlere göre daha istikrarlı ve kesintisiz bir gelişmenin yaşandığı 2003-2012 yıllarını kapsayan 10 yıllık süre, araştırma dönemi olarak belirlenmiştir. Çalışmada işletme ölçeğindeki değişkenler incelendiği için, döviz kuru, faiz oranları, enflasyon oranı, yasal mevzuat gibi temettü politikasını etkileyen ancak işletmelerin kontrol edemediği makro ekonomik parametreler kapsam dışı bırakılmıştır.

Çalışmada 2003-2012 yılları arasında hisse senetleri BiST'de işlem gören 168 sanayi işletmesine ait yıllık veriler, Kamuyu Aydınlatma Platformunun (KAP) "http://www.kap.gov.tr/" elektronik veri tabanından ve Finnet Elektronik Yayıncllık Data Limited Şirketinin "http://www.finnet.gen.tr/" kurumsal web sitesinden elde edilmiştir.

BIST sanayi sektöründeki işletmeler çalışma örneklemini oluşturmaktadır. Bu örnekleme ait işletme-yıl verilerinin satırları, bağımlı ve bağımsız değişkenlerin sütunları oluşturduğu 1680 x 44 boyutlarında bir matris elde edilmiştir. Ancak bu örnekleme ait veri içinden analize uygun olmayan verilerin ayıklanması gerekmiştir. Örnekleme sadece 2003-2012 yılları arasında kar açıklayan ve temettü dağıtımı yapan sanayi işletmeleri alınmıştır. Hisse başına karı negatif olan, temettü dağıtmayan, birleşen veya bölünen, iflas eden, kotasyondan çıkarılan ve verisi olmayan işletmeler ise örneklemden çıkarılmıştır. Verisi sıfır olan ve verisi olmayan gözlemlerin de çıkarılmasıyla 557 işletme-yıl gözlemden (satır) x 44 değişkenden (sütun) oluşan örneklem verilerini içeren matrise ulaşılmıştır. Örneklemdeki bazı işletmelerin her yıl temettü dağıtmaması, bazılarının ise 2003 yıından sonraki yıllarda halka açılarak temettü dağıtmaya başlaması dolayısıyla, her yıl temettü dağıtan işletme sayısı değişkenlik göstermektedir.

ÇDR analizine geçilmeden önce örneklem verilerinin bulunduğu matrisin satır sıraları rastgele sayılar yardımıyla rassallaştııımıştır. ÇDR analizlerinde önce modelleri oluşturmak için 557 satırlık rassallaştırımış örneklemin \%80'ine karşılık gelen ilk 446 satırı kullanılırken, örneklemin kalan \%20'sine karşılık gelen 111 satırı modellerin geçerliliğini test etmek (oluşturulan bu modellerin performansını gerçek değerler ile mukayese etmek) için kullanılmıştır. Bu veri kümeleri sırasıyla eğitim ve test kümesi olarak adlandırıımıştır.

\section{Yöntem}

Teorilerin tek başlarına temettü politikalarını açıklamada yetersiz kaldığından, ilk amaç olarak temettü dağıtım oranı ile hangi değişkenler arasında anlamlı ilişkilerin bulunduğu araştırılmıştır. Bu doğrultuda cari yıl içinde nakit ödenen brüt temettü oranı bağımlı değişken (Tablo 1), temettü bileşenlerine yönelik literatürde çeşitli teori ve faktörlerin göstergesi olarak kullanılmış 43 parametrenin önceki yıla ait verisi ise bağımsız değişken (Tablo 2) olarak belirlenmiştir. 
Mustafa Fatih ARSOY | Birol YILDIZ

Tablo 1. Analizde Kullanılan Bağımlı Değişken

\begin{tabular}{|c|c|c|c|c|}
\hline \multicolumn{2}{|c|}{ Gösterim } & \multirow{2}{*}{$\begin{array}{l}\text { Değişken adı } \\
\text { Cari Dönem Nakit } \\
\text { nen Brüt Temettü } \\
\text { Oranı }\end{array}$} & \multicolumn{2}{|r|}{ Açıklama } \\
\hline \multicolumn{2}{|r|}{$\begin{array}{l}(\mathrm{T} \\
\text { Öc }\end{array}$} & & \multicolumn{2}{|c|}{$\begin{array}{l}\text { Bir önceki yılın bilanço verilerine } \\
\text { göre cari yıl içinde ödenen nakit } \\
\text { brüt temettü miktarı / Bir öncek } \\
\text { yıla ait vergi sonrası net kâr }\end{array}$} \\
\hline \multicolumn{5}{|c|}{ Tablo 2. Analizde Kullanılan Bağımsız Değişkenler } \\
\hline Değişken & Değişken Adı & Açıklaması & & Teori/Gösterge \\
\hline $\mathrm{X} 1$ & Firma yaşı & $\begin{array}{l}\text { Firma ömrünün yıl } \\
\text { ritması }\end{array}$ & ak loga- & Yaşam döngüsü \\
\hline $\mathrm{X} 2$ & Kotasyon yılı & $\begin{array}{l}\text { Borsada işlem gör } \\
\text { sayısı }\end{array}$ & & Yaşam döngüsü \\
\hline $\mathrm{x} 3$ & $\begin{array}{l}\text { Özsermaye/Borç } \\
\text { oranı }\end{array}$ & $\begin{array}{l}\text { Toplam özsermay } \\
\text { borç oranı }\end{array}$ & plam & Finansal durum \\
\hline X4 & $\begin{array}{l}\text { Net işletme } \\
\text { sermayesi } \\
\text { devir hızı }\end{array}$ & $\begin{array}{l}\text { Net satışlar / (Dön } \\
\text { Kısa vadeli borçlar }\end{array}$ & $\begin{array}{l}\text { varlıklar- } \\
\text { ranı }\end{array}$ & $\begin{array}{l}\text { Faaliyet etkinliği, } \\
\text { Yatırım fırsatı }\end{array}$ \\
\hline $\mathrm{X} 5$ & Faiz karşılama oranı & $\begin{array}{l}\text { Faiz ve vergi önces } \\
\text { nansman giderleri }\end{array}$ & / Fi- & Likidite \\
\hline $\mathrm{x} 6$ & Nakit akışı(FCF) & $\begin{array}{l}\text { (Vergi sonrası net } \\
\text { tisman)ın logaritm }\end{array}$ & Amor- & $\begin{array}{l}\text { Serbest nakit akışı, } \\
\text { Temsil maliyetleri }\end{array}$ \\
\hline $\mathrm{X} 7$ & $\begin{array}{l}\text { Borç/Özsermaye } \\
\text { oranı }\end{array}$ & $\begin{array}{l}\text { Toplam borç /Top } \\
\text { özsermaye oranı }\end{array}$ & & Kaldıraç \\
\hline $\mathrm{x} 8$ & $\begin{array}{l}\text { FVÖK/Net Satışlar } \\
\text { oranı }\end{array}$ & $\begin{array}{l}\text { Faiz ve vergi önces } \\
\text { satışlar oranı }\end{array}$ & /Net & $\begin{array}{l}\text { Serbest nakit akışı, } \\
\text { Temsil maliyetleri }\end{array}$ \\
\hline X9 & Nakit oranı & $\begin{array}{l}\text { (Hazır değerler+M } \\
\text { değerler) /Kısa vac } \\
\text { oranı }\end{array}$ & $\begin{array}{l}\text { kul } \\
\text { borçlar }\end{array}$ & Likidite \\
\hline $\mathrm{X} 10$ & $\begin{array}{l}\text { Hazır değer oranı } \\
\text { (CTAT) }\end{array}$ & $\begin{array}{l}\text { Hazır değerler /Tc } \\
\text { varlıklar oranı }\end{array}$ & & Likidite \\
\hline $\mathrm{X} 11$ & Vergi & $\begin{array}{l}\text { Vergi ve diğer yasa } \\
\text { yükümlülükler/Ve } \\
\text { net kâroranı }\end{array}$ & ncesi & Vergi etkisi \\
\hline $\mathrm{X} 12$ & HAO & Halka açıklık aranı & & $\begin{array}{l}\text { Sahiplik yoğunluğu, } \\
\text { Temsil maliyetleri }\end{array}$ \\
\hline $\mathrm{X} 13$ & Kaldıraç oranı & $\begin{array}{l}\text { Uzun vadeli borçl } \\
\text { varlıklar oranı }\end{array}$ & Toplam & $\begin{array}{l}\text { İşlem maliyetleri, } \\
\text { Kaldıraç etkisi }\end{array}$ \\
\hline
\end{tabular}




\begin{tabular}{|c|c|c|c|}
\hline $\mathrm{X} 14$ & Ar-ge oranı & $\begin{array}{l}\text { AR-GE giderleri/Toplam } \\
\text { varlıklar oranı }\end{array}$ & $\begin{array}{l}\text { Finansman } \\
\text { hiyerarşisi, Yatırım fır- } \\
\text { satı, Yaşam döngüsü, } \\
\text { Temsil maliyetleri, } \\
\text { Serbest nakit akışı }\end{array}$ \\
\hline $\mathrm{X} 15$ & Özsermaye oranı & $\begin{array}{l}\text { Toplam özsermaye/Toplam } \\
\text { varlıklar oranı }\end{array}$ & Finansal durum \\
\hline $\mathrm{X} 16$ & Aktif kârlılığı (ROA) & $\begin{array}{l}\text { Dönem net kârı/Toplam } \\
\text { varlıklar oranı }\end{array}$ & $\begin{array}{l}\text { Kârlılık, Lintner } \\
\text { modeli, Sinyalizasyon }\end{array}$ \\
\hline $\mathrm{X} 17$ & $\begin{array}{l}\text { Özsermaye kârlılığı } \\
\text { (ROE) }\end{array}$ & $\begin{array}{l}\text { Dönem net karı/ Özsermaye } \\
\text { oranı }\end{array}$ & $\begin{array}{l}\text { Kârlılık, Lintner } \\
\text { modeli, Sinyalizasyon }\end{array}$ \\
\hline $\mathrm{X} 18$ & Net kâr marjı & Dönem net kârı/Satışlar oranı & Kârlılık \\
\hline X19 & Asit-test oranı & $\begin{array}{l}\text { (Dönen varlıklar-Stoklar)/Kısa } \\
\text { vadeli borçlar oranı }\end{array}$ & Likidite \\
\hline $\mathrm{X} 20$ & $\begin{array}{l}\text { Net işletme } \\
\text { sermayesi }\end{array}$ & $\begin{array}{l}\text { Dönen varlıklar-Kısa vadeli bor- } \\
\text { çlar }\end{array}$ & Likidite \\
\hline $\mathrm{X} 21$ & Net Satışlar & Net satış tutarı & $\begin{array}{l}\text { Büyüklük, Finans- } \\
\text { man Hiyerarşisi, } \\
\text { Yatırım fırsatları }\end{array}$ \\
\hline $\mathrm{X} 22$ & Faaliyet kârı & Faaliyet Karı & Kârlılık \\
\hline $\mathrm{X} 23$ & VSNK & Vergi sonrası dönem net kârı & $\begin{array}{l}\text { Kârlılık, Lintner } \\
\text { modeli }\end{array}$ \\
\hline $\mathrm{X} 24$ & $\begin{array}{l}\text { Brüt esas faaliyet } \\
\text { kârı }\end{array}$ & Brüt esas faaliyet karı & Kârlılık \\
\hline $\mathrm{X} 25$ & FVÖK & Faiz ve vergi öncesi kar & Kârlılık \\
\hline $\mathrm{X} 26$ & $\begin{array}{l}\text { Fiyat /Kazanç oranı } \\
\text { dönem sonu }\end{array}$ & $\begin{array}{l}\text { Dönem sonu hisse senedinin } \\
\text { piyasa fiyatı/Hisse başına kâr }\end{array}$ & $\begin{array}{l}\text { Nakit akış kalitesi, } \\
\text { Piyasa performansı }\end{array}$ \\
\hline$x 27$ & Aktif devir hızı & $\begin{array}{l}\text { Net satışlar / Toplam varlıklar } \\
\text { oranı }\end{array}$ & $\begin{array}{l}\text { Faaliyet etkinliği, } \\
\text { Yatırım fırsatı }\end{array}$ \\
\hline$X 28$ & $\begin{array}{l}\text { Duran varlık devir } \\
\text { hızı }\end{array}$ & $\begin{array}{l}\text { Net Satışlar/ Duran varlıklar } \\
\text { oranı }\end{array}$ & $\begin{array}{l}\text { Faaliyet etkinliği, } \\
\text { Yatırım fırsatı }\end{array}$ \\
\hline X29 & Toplam varlıklar & $\begin{array}{l}\text { Toplam varlıkların defter değe- } \\
\text { rinin logaritması }\end{array}$ & Büyüklük, İstikrar \\
\hline X30 & $\begin{array}{l}\text { Dönem sonu hisse } \\
\text { başına kâr }\end{array}$ & $\begin{array}{l}\text { Dönem net karı / Hisse senedi } \\
\text { sayısı }\end{array}$ & Lintner modeli \\
\hline X31 & Cari oran & $\begin{array}{l}\text { Dönen Varlıklar/ Kısa vadeli } \\
\text { borçlar }\end{array}$ & Likidite \\
\hline X32 & Aktif büyüme oranı & $\begin{array}{l}\text { Toplam varlıkların büyüme } \\
\text { oranı(\%)=Aktifler2-Ak- } \\
\text { tifler1/Aktifler1 }\end{array}$ & $\begin{array}{l}\text { Sinyalizasyon, İşlem } \\
\text { maliyetleri }\end{array}$ \\
\hline
\end{tabular}


Mustafa Fatih ARSOY | Birol YILDIZ

\begin{tabular}{|c|c|c|c|}
\hline$x 33$ & $\begin{array}{l}\text { Satış gelirleri } \\
\text { büyüme oranı }\end{array}$ & $\begin{array}{l}\text { Toplam net satış gelirlerinin } \\
\text { büyüme oranı(\%)= Net } \\
\text { Satışlar2-Net Satışlar1/Net } \\
\text { Satışlar1 }\end{array}$ & $\begin{array}{l}\text { Sinyalizasyon, Finans- } \\
\text { man Hiyerarşisi, } \\
\text { Yatırım fırsatları }\end{array}$ \\
\hline X34 & Aktif Desteği & $\begin{array}{l}\text { Duran varlıklar/Toplam } \\
\text { varlıklar oranı }\end{array}$ & $\begin{array}{l}\text { Sinyalizasyon, Yaşam } \\
\text { Döngüsü }\end{array}$ \\
\hline X35 & Toplam borç oranı & $\begin{array}{l}\text { Toplam borç/ Toplam varlıklar } \\
\text { oranı }\end{array}$ & $\begin{array}{l}\text { Kaldıraç etkisi, Yaşam } \\
\text { Döngüsü }\end{array}$ \\
\hline X36 & $\begin{array}{l}\text { Hisse senedi kapa- } \\
\text { nış bölünmemiş fi- } \\
\text { yatı }\end{array}$ & $\begin{array}{l}\text { Hisse senedinin bölünmemiş } \\
\text { kapanış fiyatının doğal logarit- } \\
\text { ması }\end{array}$ & $\begin{array}{l}\text { Büyüklük, istikrar, } \\
\text { Yaşam döngüsü }\end{array}$ \\
\hline X37 & $\begin{array}{l}\text { Dönem sonu } \\
\text { PD/DD oranı }\end{array}$ & $\begin{array}{l}\text { Hisse senedinin dönem sonu } \\
\text { piyasa değeri/ Hisse senedinin } \\
\text { dönem sonu Defter değeri } \\
\text { oranı }\end{array}$ & $\begin{array}{l}\text { Sinyalizasyon, Finans- } \\
\text { man Hiyerarşisi, } \\
\text { Yatırım fırsatları }\end{array}$ \\
\hline X38 & $\begin{array}{l}\text { Dönem sonu piyasa } \\
\text { değeri }\end{array}$ & $\begin{array}{l}\text { Firmanın dönem sonu itibari- } \\
\text { yle (toplam hisse senedi sayısı } \\
\text { x her bir hissenin piyasa fi- } \\
\text { yatı)nın logaritması }\end{array}$ & Büyüklük, istikrar \\
\hline X39 & Beta & Beta katsayısı & Risk, İşlem maliyetleri \\
\hline$X 40$ & $\begin{array}{l}\text { FAVÖK/Toplam } \\
\text { varlıklar oranı }\end{array}$ & $\begin{array}{l}\text { Faiz, amortisman ve vergi } \\
\text { öncesi kar/toplam varlıklar } \\
\text { oranın }\end{array}$ & Kârlılık \\
\hline$x 41$ & $\begin{array}{l}\text { Toplam varlık/ } \\
\text { Özsermaye oranı }\end{array}$ & $\begin{array}{l}\text { Toplam Varlıklar /Toplam } \\
\text { Özsermaye oranı }\end{array}$ & Kaldıraç \\
\hline$x 42$ & $\begin{array}{l}\text { Dönem sonu halka } \\
\text { açık piyasa değeri }\end{array}$ & $\begin{array}{l}\text { Firmanın dönem sonu itibari- } \\
\text { yle (halka açıklık oranı x top- } \\
\text { lam hisse senedi sayısı x her bir } \\
\text { hissenin piyasa fiyatı)nın loga- } \\
\text { ritması }\end{array}$ & Büyüklük, istikrar \\
\hline$x 43$ & $\begin{array}{l}\text { Geçmiş dönem } \\
\text { temettü bedeli brüt } \\
\text { toplamı }\end{array}$ & $\begin{array}{l}\text { (T-1) döneminde ödenmiş brüt } \\
\text { temettü tutarı toplamı }\end{array}$ & Lintner modeli \\
\hline
\end{tabular}

Temettü dağıtımını belirleyen birden çok açıklayıcı değişken olduğu için temettü tahmin modeli geliştirmek amacıyla çoklu doğrusal regresyon (ÇDR) analizinden yararlanılmıştır. Model kurulma aşamasında SPSS tabanlı Clementine 12.0 programı kullanılmıştır.

Modelin formülü aşağıdaki gibidir:

$Y=\beta o+\beta I X I+\ldots+\beta n X n+\varepsilon$ 
Y: bağımlı değişken,

Xi: bağımsız değişkenler,

$\beta i$ : tahmin edilecek parametreler

$\varepsilon$ : hata terimi

Çalışmanın ikinci aşamasında, bağımlı değişken olan cari dönem nakit ödenen brüt temettü oranını en iyi tahmin eden modele ulaşmak için, ÇDR ile farklı modeller oluşturulmuştur. Buna göre tüm değişkenlerin kullanılması ile oluşturulan 4 ve boyut indirgeme sonrası elde edilen değişkenlerle oluşturulan 24 adet ÇDR modeli ile toplamda 28 model geliştirilmiştir.

Çalışmamızda 43 bağımsız değişkenin tümünün girdi olarak kullanıldığı ilk 4 ÇDR modellerinde, sırasıyla enter, forwards, backwards ve stepwise olmak üzere dört değişken seçim yöntemi de kullanıımışır. Bu yöntemler farklı değişkenleri modellerine dahil etmişlerdir. Bu modellerin tahmin hataları da doğal olarak farklı olmuştur.

ÇDR analizinde değişken sayısını azaltmak ve değişkenler arası ilişkilerdeki yapıyı ortaya çıkarmak, diğer bir ifadeyle birbirleriyle ilişkili çok sayıdaki değişkeni az sayıda, anlamlı ve birbirinden bağımsız faktörler haline getirmek amacıyla, yaygın olarak kullanılan boyut indirgeme tekniklerinden biri olan faktör analizinden yararlanılmıştır. Olası en iyi modele ulaşabilmek için, Clementine 12.0 programının sunduğu olanaklar çerçevesinde 5 faktörden 10 faktöre kadar faktör analizi yapılmıştır.

Faktör analiz ile yapılan boyut indirgeme ardından 43 bağımsız değişken yerine 5,6 , 7, 8, 9 ve 10 faktörün girdi olarak kullanıldığı farklı ÇDR modelleri yapılandırılmışıı. Bu modellerin geliştirilmesi sırasında da her bir ÇDR modeli için enter, forwards, backwards ve stepwise olmak üzere dört farklı değişken seçim yönteminin kullanımı ile 24 farklı model ortaya çıkmışır.

28 ÇDR modelinin her biri, eğitim verileri kullanılarak oluşturulmuş ve ardınan test verileri üzerinden performansları ölçülmüştür. ÇDR modellerinin performansını ölçmek için, modeller ile elde edilen sonuçların gerçek değere ne kadarlık yakınlık gösterdiğini ifade eden ortalama mutlak hata yüzdesi - OMHY (Mean Absolute Percentage Error - MAPE) kullanılmıştır. Ortalama mutlak sapma yüzdesi olarak da bilinen $\mathrm{OMHY}$, istatistikte ve özellikle de trend tahmininde zaman serileri değerlerinin bulunmasında doğruluk ölçüsü olarak kullanılan bir yöntemdir. Yakınsama hatasını oran cinsinden açıkladığı için genelleştirebilen $\mathrm{OMHY}$ ile, oluşturulan tüm modellerin performansı kıyaslanmıştır. Yakınsama doğruluğu, aşağıdaki formül ile yüzde olarak açıklanmaktadır:

$O M H Y=\frac{1}{n} \sum_{t=1}^{n}\left|\frac{A_{t}-F_{t}}{A_{t}}\right|$ (2)

$A_{t}=t^{\prime}$ ninci birimin gerçek değeri,

$F_{t}=t^{\prime}$ ninci birimin tahmin değeri

tahmin hatası temelinde kıyaslanmıştır. 


\section{Bulgular}

Çalışmamızdaki 28 ÇDR modelinin her birinin test verisi ile ulaştığı OMHY değeri Tablo 3'de görülmektedir. Gerçek y değerini \% 2,44950083 hata ile tahmin başarısı gösteren 3.backwards adlı ÇDR modelinin, tüm modeller arasında en yüksek performans göstererek, en küçük OMHY değerine sahip olduğu gözlenmiştir.

Tablo 3. Test Verisinde OMHY Değerlerinin Kıyaslanması

\begin{tabular}{|c|c|c|}
\hline & ÇDR Modelleri & $O M H Y(\%)$ \\
\hline \multirow{4}{*}{$\begin{array}{l}\text { Boyut İndirmesi Yapılma- } \\
\text { dan Oluşturulan Modeller }\end{array}$} & 1.enter & 2.544452744 \\
\hline & 2.stepwise & 2.544819747 \\
\hline & 3. backwards * & 2.449500826 \\
\hline & 4.forwards & 2.544819747 \\
\hline \multirow{22}{*}{$\begin{array}{l}\text { Faktör Analizi Sonrasında } \\
\text { Oluşturulan Modeller }\end{array}$} & 5.1.enter & 3.273269143 \\
\hline & 5.2.stepwise & 3.294488488 \\
\hline & 5.3.backwards & 3.294488488 \\
\hline & 5.4.forwards & 3.294488488 \\
\hline & 6.1.enter & 3.405097839 \\
\hline & 6.2.stepwise & 3.307724365 \\
\hline & 6.3.backwards & 3.307724365 \\
\hline & 6.4.forwards & 3.307724365 \\
\hline & 7.1.enter & 3.475037293 \\
\hline & 7.2.stepwise & 3.378342328 \\
\hline & 7.3.backwards & 3.389581111 \\
\hline & 7.4.forwards & 3.378342328 \\
\hline & 8.1.enter & 3.061358302 \\
\hline & 8.2.stepwise & 2.983419175 \\
\hline & 8.3.backwards & 2.983419175 \\
\hline & 8.4.forwards & 2.983419175 \\
\hline & 9.1.enter & 3.066319892 \\
\hline & 9.2.stepwise & 2.902056762 \\
\hline & 9.3.backwards & 3.052476759 \\
\hline & 9.4.forwards & 2.902056762 \\
\hline & 10.1.enter & 3.167733541 \\
\hline & 10.2.stepwise & 3.01863445 \\
\hline
\end{tabular}




$\begin{array}{ll}\text { 10.3.backwards } & 3.01863445 \\ \text { 10.4.forwards } & 3.01863445\end{array}$

ÇDR modelinin kurulmasında Clementine 12.0 programı, önce 43 bağımsı değişkenin hepsini modele dahil etmiş daha sonra en güçsüz bağımsız değişkeni modelden çıkarıp regresyonu tekrar hesaplamıştır. Bağımsız değişkenler arasında 0,80 ve üzerinde korelasyon varsa, bu durum çoklu bağıntı probleminin bir göstergesi olacağından program bu değişkenleri modelden tek tek çıkarmaktadır. Dolayısıyla sadece açıklama gücü en yüksek bağımsız değişkenler modelde kalıncaya dek, bağımsız değişken çıkarma ve ekleme süreci de-

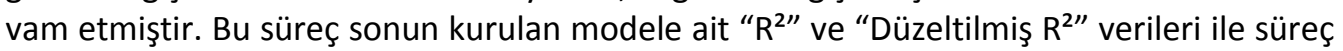
sonunda ulaşılan 11 değişkenden Tablo 4'de görülmektedir. Tablo 4'de göre bağımlı değişkendeki değişimin \% 60,3'ü modele dahil edilen 11 bağımsız değişken tarafından açıklanırken, geriye kalan \%39,7'lik kısmı hata terimi vasıtasıyla modele dahil etmediğimiz değişkenler tarafından açıklandığı görülmektedir.

Modelin bir bütün olarak anlamlı olup olamadığını test etmeye yarayan Tablo 4'deki Varyans Analizinde (ANOVA), modelin 62,363 F değeri ile modelin bir bütün olarak her düzeyde anlamlı olduğunu göstermektedir $(p=0,000)$.

Tablo 4. Backwards Modeli Varyans Analizi Tablosu

\begin{tabular}{|c|c|c|c|c|c|}
\hline \multicolumn{6}{|c|}{ ANOVA } \\
\hline & Sum of Squares & $d f$ & Mean Square & $F$ & Sig. \\
\hline $\begin{array}{l}\text { Regres- } \\
\text { sion }\end{array}$ & 19679577,381 & 11 & 1789052,489 & 62,363 & 0,000 (ah) \\
\hline Residual & 12450513,168 & 434 & 28687,818 & & \\
\hline Total & 32130090,548 & 445 & & & \\
\hline $\begin{array}{l}\text { Bağımlı D } \\
\text { Tahminci } \\
\text { SYON YA } \\
\text { ÖZSERM } \\
\text { TiF KARLI }\end{array}$ & $\begin{array}{l}\text { : CARI DÖNEM N } \\
\text { it), FAIZ KARŞILA } \\
\text { SENEDI KAPANIŞ } \\
\text { LILIĞI (ROE), TOP } \\
\text { A), TOPLAM VARL }\end{array}$ & $\begin{array}{l}\text { TÖDE } \\
\text { ORAN } \\
\text { DLÜNN } \\
\text { M VAR } \\
\text { AR }\end{array}$ & $\begin{array}{l}\text { BRÜT TEMETTÜ } \\
\text { AT / KAZANÇ OR } \\
\text { Ş, CTAT (Hazır De } \\
\text { ZSERMAYE ORAI }\end{array}$ & $\begin{array}{l}\text { ANI } \\
\text { II DÖNEM } \\
\text { /Top.Varlı } \\
\text { NET SATIŞ }\end{array}$ & $\begin{array}{l}\text { UU, KOTA- } \\
\text { HBK, AK- }\end{array}$ \\
\hline
\end{tabular}

Tablo 5'deki Katsayılar Tablosu'nda ulaşılan modelin parametre değerleri ve bunlara ilişkin t değerleri görülmektedir. Parametrelere ait $\mathrm{t}$ istatistik değerlerinden modele dahil edilen bağımsız değişkenlerin (toplam varlıklar hariç) ayrı ayrı \%5 anlamlılık düzeyinde anlamlı olduğu anlaşılmaktadır. Yukarıda belirtilen $\mathrm{F}$ istatistiği modelin bir bütün olarak anlamllığını test etmek için kullanılırken, $\mathrm{t}$ istatistiği değişkenlerin ayrı ayrı anlamlı olup olamadıklarını test etmek amacıyla kullanılır. Tablo 5 'den görüleceği gibi sabit terim 39,255 olarak bulunmuştur. Bunun anlamı 11 bağımsız değişkenin toplamı sffir bile olsa firma 39,255 birimlik nakit brüt temettü ödemesi yapmaktadır. Bağımsız değişkenlere bakıldığında, örneğin "kotasyon yaşı”na ait parametre değeri 3,172'dir. Kotasyon yaşındaki bir birimlik artı̧̧, nakit ödenen brüt temettü miktarını 3,172 birim artırmaktadır. Buna karşın aktif karlııktaki bir birimlik artı̧ nakit ödenen brüt temettü miktarını 10,268 birim azaltmaktadır. 
Tablo 5'deki Katsayılar Tablosu'nda yeralan Beta değerleri işaretine bakılmaksızın bağımsız değişkenlerin önem sırasını göstermektedir. En yüksek Beta değerine sahip “Hisse Senedi Kapanış Bölünmemiş" değişkeni, en önemli bağımsız değişkendir ve her düzeyde anlamlıdır. Bunu sırasıyla "Aktif Karlılı̆ı̆”, “Özsermaye Karlılığı”, "HBK”, “CTAT”, “Net Satışlar”, "Toplam Varlık Özsermaye Oranı”, "Toplam Varlıklar" değişkenlerinin takip ettiği görülmektedir.

Tablo 5.Backwards Modeli Katsayılar Tablosu

\begin{tabular}{|c|c|c|c|c|c|}
\hline \multicolumn{6}{|c|}{ Katsayılar } \\
\hline & \multirow{2}{*}{\multicolumn{2}{|c|}{$\begin{array}{c}\text { Standardize Edilmemiş } \\
\text { Katsayılar }\end{array}$}} & \multirow{3}{*}{$\begin{array}{c}\text { Standart } \\
\text { Katsayılar } \\
\text { Beta }\end{array}$} & \multirow{3}{*}{$\mathrm{t}$} & \multirow{3}{*}{ Sig. } \\
\hline & & & & & \\
\hline & B & Std. Error & & & \\
\hline (Sabit) & 39,255 & 44,838 & & 0,875 & 0,382 \\
\hline KOTASYON YAŞI & 3,172 & 1.469 & 0,066 & 2,159 & 0,031 \\
\hline FAIZ KARŞILAMA ORANI & $-0,002$ & 0,001 & $-0,086$ & $-2,440$ & 0,015 \\
\hline $\begin{array}{l}\text { CTAT(Haz.Değ. } \\
\text { /Top.Var.) }\end{array}$ & 363,559 & 88,209 & 0,141 & 4,122 & 0,000 \\
\hline AKTIF KARLILIK (ROA) & $-10,268$ & 3,822 & $-0,310$ & $-2,687$ & 0,007 \\
\hline ÖZSERMAYE KARLILIĞI & 8,025 & 2,889 & 0,302 & 2,778 & 0,006 \\
\hline NET SATIŞLAR & $8,90 \mathrm{E}-009$ & 0,000 & 0,134 & 2,384 & 0,018 \\
\hline FIYAT / KAZANÇ ORANI & $-0,340$ & 0,168 & $-0,065$ & $-2,018$ & 0,044 \\
\hline TOPLAM VARLIKLAR & $-1,27 E-008$ & 0,000 & $-0,104$ & $-1,835$ & 0,067 \\
\hline HBK & 7,369 & 3,513 & 0,227 & 2,098 & 0,037 \\
\hline $\begin{array}{l}\text { HIS.SEN.KAP. } \\
\text { BÖLÜNMEM }\end{array}$ & 1,373 & 0,264 & 0,546 & 5,194 & 0,000 \\
\hline TOP. VAR. ÖZSER. ORANI & $-54,663$ & 24,935 & $-0,112$ & $-2,192$ & 0,029 \\
\hline
\end{tabular}

Bağımlı Değişken: CARI DÖNEM NAKIT ÖDENEN BRÜT TEMETTÜ ORANI

\section{Sonuç}

Hisse senedi yatırımı yapan, özellikle işletmelerin orta ve uzun vadeli temettü politikasına göre pozisyon alan yatırımcılar için, işletmelerin dağıtacağı temettü büyük önem taşımaktadır. Dağııılacak temettü oranı özellikle makro ekonomik ve jeopolitik problemlerin olduğu dönemlerde istikrarlı getiri bekleyen bu yatırımcılar tarafından çok yakından takip edilmektedir.

Bu çalışmada da nakit ödenen brüt temettü oranını açıklayan etkenleri bulmak ve ödenecek temettü oranını tahmin etmek amaçlanmıştır. Araştırmada 2003-2012 yılları arasında BisT'de işlem gören sanayi işletmelerinin bilanço ve gelir tablolarından belli kriterlere göre seçilen finansal veriler kullanılmıştır. En iyi tahmini yapan modeli ortaya çıkarmak amacıyla boyut indirgeme yapılan ve yapılmayan farklı çoklu doğrusal regresyon modelleri oluşturulmuş ve bu modellerin tahmin performansı ortalama mutlak hata yüzdesi temel alınarak karşılaştııı ış̧tır. 
Çalışma sonucunda bağımlı değişken olan cari dönem nakit ödenen brüt temettü oranını $\% 2,44950083$ hata ile tahmin eden ÇDR modeli elde edilmiştir. Model incelendiğinde hisse senedi kapanış (bölünmemiş), hisse başına kâr, özsermaye kârlıı̆̆, hazır değer oranı, aktif kârlılı̆ı, net satışlar, toplam varlık özsermaye oranı ve toplam varlıklar bağımsız değişkenlerinin cari dönem nakit ödenen brüt temettü oranını tahmin etmede etkili değişkenler olduğu ortaya çıkmıştır.

Bu çalışmada, literatürdeki diğer araştırmalar ile uyumlu olarak, istikrarlı büyüme ve ölçek ekonomisine sahip olma, yüksek kârlılık seviyesini her dönem arttırma, yüksek likiditeye ve sağlam bir nakit akımına sahip olma özelliklerinin sanayi şirketlerinde nakit temettü ödemesini belirleyen temel etkenler olduğunu göstermektedir. Bu bağlamda araştırmanın sinyalizasyon, serbest nakit akışı ve yaşam döngüsü teorileri ile Lintner modelini desteklediği görülmektedir.

Bu araştırmada Türkiye' de halka açık sanayi işletmelerinde temettü dağıtımını belirleyen temel etkenlerin neler olduğu, temettü politikasında hangi teorilerin geçerli olduğu ortaya konularak teoriye katkı sağlanmaya çalışımıştır. Ayrıca Türkiye'de işletmelerin bireysel olarak dağıtacağı nakit temettü oranının hangi bileşenlere bağlı olduğunu açıklayan ilk çalışma olması ve sermaye piyasalarında yatırım kararı alınırken yararlanılabilecek somut bir araç sağlaması bakımından, çalışmanın literatürdeki diğer çalışmalardan ayrıldığı söylenebilir.

Temettü dağıtımını belirleyen etkenlere ilişkin yapılacak sonraki çalışmalarda, veri setinin, sürenin ve kapsamın daha geniş tutulması, işletme dışı değişkenlerin de araştırma modellerine dâhil edilmesi ve farklı istatistiksel modelleme yöntemlerinin kullanılması uygun olacaktır.

\section{Kaynaklar}

Abdoua, Hussein A., John, Pointon, Ahmed, El-Masryb, Moji, Olugbodeb ve Roger, J. Lister (2012). A Variable Impact Neural Network Analysis of Dividend Policies and Share Prices of Transportation and Related Companies, Journal of International Financial Markets, Institutions \& Money,22,796-813.

Abuhommous, Ala'a Adden, Awni (2013). Financial Constraints, Capital Structure and Dividend Policy: Evidence from Jordan, Basılmamış Doktora Tezi, Brunel University School of Social Sciences.

Adaoğlu, Cahit (2000). Instability in the Dividend Policy of the Istanbul Stock Exchange (ISE) Corporations: Evidence from an Emerging Market, Emerging Markets Review, 1(3), 252-270.

Aivazian, V., Booth, I. ve Cleary, S. (2003). Do Emerging Market Firms Follow Different Dividend Policies From U.S. Firms?, Journal of Financial Research, 26(3), 371-387.

Al-Kuwari, Duha (2009). Determinants of the Dividend Policy in Emerging Stock Exchanges:The Case of GCC Countries, Global Economy \& Finance Journal, 2(2), 38-63.

Allen, Franklin, Antonio E., Bernardo ve Ivo, Welch (2000). A Theory of Dividends Based on Tax Clienteles, Journal of Finance, 55, 2499-2536. 
Mustafa Fatih ARSOY | Birol YILDIZ

Ang, James S., David, W. Blackwell ve William, L. Megginson (1991). The Effect of Taxes on the Relative Valuation of Dividends and Capital Gains: Evidence from Dual-Class British Investment Trusts, Journal of Finance, 46, 383-399.

Baker, H. Kent, E. Theodore, Veit ve Gary E., Powell (2001). Factors Influencing Dividend Policy Decisions of Nasdaq Firms, The Financial Review, 38, 19-37.

Baker, H. Kent, Gary E., Powell ve E. Theodore, Veit (2002). Revisiting the Dividend Puzzle:Do All of the Pieces Now Fit?, Review of Financial Economics, 11, 241-261.

Baker, H. K. ve Smith, D. M. (2006). In Search of a Residual Dividend Policy, Review of Financial Economics, 15(1), 1-18.

Baker, M. ve Wurgler, J. (2004a). A Catering Theory of Dividends, Journal of Finance, 59, 1125-1165.

Baker, M. ve Wurgler, J. (2004b). Appearing and Disappearing Dividends: The Link to Catering Incentives, Journal of Financial Economics, 73, 271-288.

Bancel, F., Bhattacharyya, N. ve Mittoo, U.R. (2005). Cross-Country Determinants of Payout Policy: A Survey of European Firms, Working Paper, SSRN Working Paper Series.

Banyi, Monica L. ve Kathleen, M. Kahle (2013). Declining Propensity to Pay? A Re-examination of the Life Cycle Theory, Journal of Corporate Finance, 27, 345-366.

Benito, A. ve Young, G. (2003). Hard Times of Great Expectations? Dividend Omissions and Dividend Cuts by UK Firms, Oxford Bulletin of Economics and Statistics, 65, 531-554.

Bhattacharya, Sudipto (1979). Imperfect Information, Dividend Policy, and the Bird in the Hand Fallacy, Bell Journal of Economics, 10, 259-270.

Bishop, Stephen, R., Harvey, R., Crapp, Robert, W., Faff ve Garry J., Twite (2000). Corporate Finance, Prentice Hall Inc., Sydney.

Brav, A., J. R., Graham, C. R., Harvey ve R., Michaely (2005). Payout Policy in the $21^{\text {st }}$ Century, Journal of Financial Economics, 77(3), 483-527.

Brennan, Michael J. (1970). Taxes, Market Valuation and Corporate Financial Policy, National Tax Journal, 23, 417-442.

Brockman, P. ve Unlu, E. (2009). Dividend Policy, Creditor Rights, and The Agency Costs of Debt, Journal of Financial Economics, 92(2), 276-299.

Coulton, J.J. ve Ruddock, C. (2011). Corporate Payout Policy in Australia and a Test of the Life-Cycle Theory, Accounting and Finance, 51(2), 381-407.

Crutchley, Claire ve Hansen, Robert (1989). A Test of the Agency Theory of Managerial Ownership, Corporate Leverage and Corporate Dividends, Financial Management, 18(4), 36-46. 
Çelik, Sibel (2013). Kar Payı Politikası ve Yaşam Döngüsü Teorisi: IMKB İmalat Sektöründe Ampirik Bir Uygulama, Anadolu Üniversitesi Sosyal Bilimler Dergisi.

DeAngelo, Harry ve Linda, DeAngelo (2006). The Irrelevance of the MM Dividend Irrelevance Theorem, Journal of Financial Economics, 79, 293-316.

DeAngelo, Harry, Linda, DeAngelo ve J., Skinner (2004). Are Dividends Disappearing? Dividend Concentration and the Consolidation of Earnings, Journal of Financial Economics, 72, 425-456.

DeAngelo, Harry, Linda, DeAngelo ve L., Stulz (2006). Dividend Policy and the Earned/Contributed Capital Mix: a Test of the Life-Cycle Theory, Journal of Financial Economics, 81, 227-254.

Denis, J.Denis ve Igor, Osobov (2008). Why Do Firms Pay Dividends? International Evidence on the Determinants of Dividend Policy, Journal of Financial Economics, 89(1), 62-82.

Diamond, James J. (1967). Earnings Distribution and the Valuation of Shares: Some Recent Evidence, Journal of Financial and Quantitative Analysis, 2, 15-30.

Dong, Ming, Chris A., Robinson ve Chris, Veld (2005). Why Individual Investors Want Dividends, Journal of Corporate Finance, 12(1), 121-158.

Easterbrook, Frank H. (1984). Two Agency Costs Explanations of Dividends, American Economic Review, 74, 650-659.

Fama, E. F. ve Babiak, H. (1968). Dividend Policy: An Emprical Analysis, Journal of the American Statistical Association, 63(324),1132-1161.

Fama, Eugene ve Kenneth, French (2001). Disappearing Dividends: Changing Firm Characteristics or Lower Propensity to Pay?, Journal of Financial Economics, 60(1), 3-43.

Farrelly, G., E, Baker, H. K. ve Edelman, R., B. (1986). Corporate Dividends: Views of the Policymakers, Akron Business Economy Review, 17(4), 62-74.

Fatemi, Ali ve Recep, Bildik (2012). Yes, Dividends are Disappearing: Worldwide Evidence Journal of Banking \& Finance, 36, 662-677.

Fazzari, Steven M., R. Glenn, Hubbard ve Bruce C., Petersen (1988). Financing Constraints and Corporate Investment, Brooking Papers on Economic Activity, 1, 141-195.

Ferris,P., Sen, N. ve Unlu, E. (2009). An International Analysis of Dividend Payment Behavior, Journal of Business Finance and Accounting, 36(3-4), 496-522.

Gill, Amarjit, Nahum, Biger ve Rajendra, Tibrewala (2010). Determinants of Dividend Payout Ratios: Evidence from United States, The Open Business Journal, 3,8-14.

Goergen, M., Renneboog, L. ve Da Silva, L. C. (2005). When do German Firms Change their Dividends?, Journal of Corporate Finance, 11(1-2), 375-399. 
Mustafa Fatih ARSOY | Birol YILDIZ

Gordon, Myron J. (1962). The Savings, Investment and Valuation of a Corporation, The Review of Economics and Statistics, 44, 37-51.

Gordon, Myron J. ve Eli, Shapiro (1956). Capital Equipment Analysis: The Required Rate of Profit, Management Science, 3, 102-110.

Grullon, G., R. Michaely ve B. Swaminathan (2002). Are Dividend Changes a Sign of Firm Maturity, Journal of Business, 75, 387-424.

Holder, Mark E., Frederick W., Langrehr ve J. Lawrence, Hexter (1998). Dividend Policy Determinants: An Investigation of the Influences of Stakeholder Theory, Financial Management, 27, 73-82.

Huang, J.J., Shen, Y. ve Sun, Q. (2010). Nonnegotiable Shares, Controlling Shareholders, And Dividend Payments in China, Journal of Corporate Finance, 17(1), 122-133.

Issa, Ayman i..F. (2012). The Determinants of Dividend Policy: Evidence from Malaysian Firms, Basılmamış Yüksek Lisans Tezi, University Utara Social Science (Finance).

Jensen, Gerald R., Donald P., Solberg ve Thomas S., Zorn (1992). Simultaneous Determination of Insider Ownership, Debt and Dividend Policies, Journal of Financial and Quantitative Analysis, 27, 274-263.

Jensen, Michael C. (1986). Agency Costs of Free Cash Flow, Corporate Finance, and Takeovers, American Economic Review, 76, 323-329.

Jeong, Jinho (2008). An Investigation of Dynamic Dividend Behavior in Korea, Working Paper, Division of Business Administration, Korea University.

Jeong Jinho (2013). Determinants of Dividend Smoothing in Emerging Market: The case of Korea, Emerging Markets Review, 17, 76-88.

John, Kose ve Joseph, Williams (1985). Dividends, Dillution, and Taxes: A Signalling Equilibrim, Journal of Finance, 40, 1053-1070.

Kania, S.I ve Bacon, F.W. (2005). What Factors Motivate the Corporate Dividend Decision?, ASBBS E-Journal, 1(1), 97-107.

Khan, T. (2006). Company Dividends and Ownership Structure: Evidence from UK Panel Data, The Economic Journal, 116(510,172-189.

Kim, Hyunjoon ve Zheng, Gu (2009). Financial Features of Dividend-Paying Firms in the Hospitality Industry: A Logistic Regression Analysis, International Journal of Hospitality Management, 28, 359-366. 
Kuo, Jing-Ming, Dennis, Philip ve Qingjing, Zhang (2013). What Drives the Disappearing Dividends Phenomenon?, Journal of Banking \& Finance, 37, 3499-3514.

LaPorta, R., F., Lopez-de-Silanes, A., Schliefer ve R. Vishny (2000). Agency Problems and Dividend Policies Around the World, Journal of Finance, 55(1), 1-34.

Lang, Larry H. P. ve Robert H., Litzenberger (1989). Dividend Announcements: Cash Flow Signalling and Free Cash Flow Hypothesis, Journal of Financial Economics, 24, 181-191.

Laub, P. Michael (1976). On the Informational Content of Dividends, Journal of Business, 49, 73-80.

Leary, M.T. ve Michaely, R. (2011). Determinants of Dividend Smoothing: Empirical Evidence, Review of Financial Studies, 24, 3197-3249.

Li, W. ve Lie, E. (2006). Dividend Changes and Catering Incentives, Journal of Financial Economics, 80, 293-308.

Lintner, John (1956). Distribution of Incomes of Corporations Among Dividends, Retained Earnings, and Taxes, American Economic Review, 46, 97-113.

Litzenberger, Robert H. ve Krishna, Ramaswamy (1979). The Effect of Personal Taxes and Dividends on Capital Asset Prices, Journal of Financial Economics, 7, 163-195.

Ma, Tao (2012). Corporate Dividend Decisions, Basılmamış Doktora Tezi, London City University.

Michael, A. (1979). Industry Influence on Dividend Policy, Financial Management, 8(3), 22-26.

Mitton, T. (2004). Corporate Governance and Dividend Policy in Emerging Markets, Emerging Markets Review, 5,(4), 409-426.

Parua, Anupam ve Arindam, Gupta (2009). Dividend History and Determinants in Selected Indian Companies: a Study During 1993-'94 to 2004-'05, the Australasian Accounting Business \& Finance Journal, 3(4), 45.

Pettit, R. Richardson (1972). Dividend Announcements, Security Performance and Capital Market Efficiency, Journal of Finance, 27, 993-1007.

Pettit, R. Richardson (1977). Taxes, Transactions Costs and the Clientele Effect of Dividends, Journal of Financial Economics, 5, 419-436.

Poterba, James M. ve Lawrence H., Summers (1984). New Evidence That Taxes Affect the Valuation of Dividends, Journal of Finance, 39, 1397-1415.

Pruitt, S.W. ve Gitman, L.J. (1991). The Interactions Between the Investment, Financing and Dividend Decisions of Major US Firms, Finance Review, 26(3), 409-30.

Renneboog, Luc ve Grzegorz, Trojanowski (2005). Patterns in Payout Policy and Payout Channel Choice of UK Firms in the 1990s, Working Paper, Tilburg University ECGI Working Paper Series in Finance. 
Renneboog, Luc ve Grzegorz, Trojanowski (2010). Patterns in Payout Policy and Payout Channel Choice, Journal of Banking and Finance, 35(6), 1477-1490.

Rozeff, Michael S. (1982). Growth, Beta and Agency Costs as Determinants of Dividend Payout Ratios, The Journal of Financial Research, 5, 249-259.

Salehi, Mahdi, Behad, Kardan ve Zohresh, Aminifard (2012). Effective Components on the Forecast of Companies' Dividends Using Hybrid Neural Network and Binary Algorithm Model, Indian Journal of Science and Technology, 5, 9.

Seida, Jim A. (2001). Evidence of Tax-Clientele-Related Trading Following Dividend Increases, Journal of the American Taxation Association, 23, 1-21.

Von Eije ve H., Megginson, W. (2006). Dividend Policy in the European Union, Unpublished Working Paper, University of Oklahoma.

Von Eije, H. ve Megginson, W.L. (2008). Dividends and Share Repurchases In the European Union, Journal of Financial Economics, 89(2), 347-374.

Walter, James E. (1963). Dividend Policy: Its Influence on the Value of the Enterprise, Journal of Finance, 18, 280-291.

Woolridge, J. Randall (1983). Dividend Changes and Security Prices, Journal of Finance, 38, 16071615. 